\title{
Semiotic resources in the development of early probabilistic thinking when teaching mathematics as storytelling
}

\author{
Theodosia Prodromou \\ School of Education, University of New England, Armidale NSW 2351, Australia
}

Email address:

theodosia.prodromou@une.edu.au

\section{To cite this article:}

Theodosia Prodromou. Semiotic Resources in the Development of Early Probabilistic Thinking When Teaching Mathematics as Storytelling. International Journal of Elementary Education. Vol. 3, No. 6, 2014, pp. 115-120. doi: 10.11648/j.ijeedu.20140306.11

\begin{abstract}
This article deals with the question of the development of probabilistic thinking in young students when teaching mathematics as storytelling. In this study, our research is framed by the theory of learning as an objectification process (Radford, 2008) that is accomplished by the interaction of material and ideational elements such as, mathematical objects, signs, speech, gestures, forms of imagination, action with signs. Results from this study reveal some patterns of probabilistic reasoning used by young students.
\end{abstract}

Keywords: Probabilistic Thinking, Mathematics, Storytelling, Objectification Process, Mathematical Objects, Signs, Speech, Gestures, Forms of Imagination, Actions with Signs, Probability, Elementary Students

\section{Introduction}

In primary education it is crucial for the learning of mathematics to be connected to children everyday experiences and make sense to them. Children's literature is considered as a didactical tool which has the potential to provide children with an appealing context in which the problems, situations and questions they encounter are meaningful to them [1].

A number of studies have provided evidence about the positive role of the characteristics of a storytelling [2]. In particular, [2] explain that they support teaching mathematics as Storytelling in the mathematics classroom to: (a) achieve an environment of imagination, emotion, and thinking, (b) make mathematics more enjoyable and more memorable, and (c) engage students in a mathematical activity, to make them think and explore, and to help them understand concepts and ideas. There is also an abundance of anecdotal data that suggests "telling a story creates more vivid, powerful and memorable images in a listener's mind than does any other means of delivery of the same material" [3].

Researchers in the field of mathematics have recently examined the semiotic resources used in classrooms when students work on problems and explorations related to various mathematical concepts [4]; [5]; [6]; [7]; [8]).
However, despite the growing research in the effects of various semiotic means that are utilised for the sense making of mathematical concepts, little is known about how mathematical thinking develops in young students when mathematics is taught as storytelling.

This article seeks to contribute to this research question through the analysis of data collected in the course of a cross-national based research program between Italy and Australia.

\section{Theoretical Framework}

Generally speaking, developmental questions of this kind are difficult to deal with and not easily investigated. They can only be formulated against the backdrop of particular theoretical views about thinking and development. In this study, our research is framed by the theory of learning as an objectification process [6] that is developed by drawing on the theoretical Vygotskian perspective on teaching and learning. The theory of learning is an objectification process that is accomplished through a reflexive mediated activity ascribed by Radford's [7] cultural-semiotic approach. The reflexive mediated activity includes mathematical objects, semiotic resources, individuals' consciousness, and intentional acts, within social practice and a cultural and historical dimension. The complexity of the objectification process requires 
studying the notion of signs and going beyond their representational role, as signs culturally mediate activity and direct the individual's action towards the mathematical object. Signs include gestures, speech and inscriptions (such as graphs, formulas, tables and drawings) that play a vital role in the process of sense-making that "goes from the use of signs (marks, names and the like) as pointers of attention to more and more complex presentation and representation systems involving new signs, meanings and layers of generalization" ([9], p. 81). Within this context, to ask the question about how mathematical thinking develops in young students, when mathematics is taught as storytelling, is to ask a twofold question: (1) the first aspect is about students' material-ideational components of thinking and the form of new structural relationships between these components as illustrated by students' drawings; (2) the second aspect concerns the way that these relationships are organised and re-organised. Taking into account, that the objectification of knowledge is a cultural-semiotic approach the development of mathematical knowledge is cultural; we simply attempted to answer the twofold question of this study. In this article, however, at this stage, our research questions are concerned the appearance of new relationships of students' material-ideational components of thinking as illustrated by students' drawings of the story; and the manner that these relationships are organised and re-organised. It is with this theoretical framework that the development of young students' thinking about the possible outcomes of chance experiments and assigning to them numerical values is investigated in the following sections.

\section{Methodology}

A purposive sample was selected, comprising of 50 students in Grade 3, (ranging in age from nine to ten years old) of an elementary school in NSW in Australia. Students of this age in Australia are only expected to "conduct chance experiments, identify and describe possible outcomes and recognise variation in results" ([10], p. 22).

These data were collected out of classroom time. The author invited students to listen to a story (Figure 1) and reflect on their thinking while drawing. Each session lasted approximately one hour and was conducted with ten students; in total, the author spent 5 sessions, one working with each group of ten students.

Once upon a time, there was a beautiful princess who lived happily in her father's kingdom, Fantasyland Life in the Fantasylandwas full of joy and peace, but one day the princess was walking in the garden of her castle when she found a mysterious letter beside the ancient oak that wrote; "I am Lord Red rabbit. I have impprisonedyour prince in a tower. Don't worry: I promise that, if you would play with me, nothing would happen to the prince. Ride a horse towards the forest. You'll find indications along the joumey". Lord Red rabbit was a huge red rabbit, famous for his complex and mysterious games. The princess had to accept the challenge! After some hour of riding, she was at a crossroads. And there it was! She found close to her horse's foot a box and inside the box there was a message for the princess and a die. The message said: "If you are reading this letter, it means that you have accepted the challenge. In the container there is a die. Roll it once. If you get an even number ( 2 or 4 or 6), tum right. If you get an odd number ( 1 or 3 or 5 ), tum left." The princess rolled the die. Dear students pretendthat youare the princess and get the container that is in front of you, find a die, roll the die and draw princess's joumey. Follow and help the princess to rescue the prince.

If the princess gets an even number ( 2 or 4 or 6 ). she tums right. She flips a coin. If she gets head, she continues; if she gets tails she must retum back to the castle. If the princess gets tails: she travels along the forest and finally she arives at the tower entrance. At the foot of the tower, she finds another message: "Dear princess, There is only one obstacle betweenyou and the prince. You'll find a die. Before rolling it, choose a number. Roll the die. If you roll your chosen number the door of the tower will open. If you do not roll your chosen number the door of the tower will not open and youhave to retum back to your castle and begin the travel again from there."

If the princess gets an odd number ( 1 or 3 or 5 ), she tums left. She then gets a container and she reads a message: "Dear princess, in the container you'll find 9 counters: 4 red, 2 black and 3 blue.

Draw a counter from the container. If you choose a red counter, continue along this road and you'll find the prince. If the counter is black, go back to the castle and begin the travel again from there. If the counter is blue, take another counter (but do not retum the blue counter back into the container)."

Figure 1. The story told to the students

In order to accomplish the aim of this paper, we have focused here only on the signs, and inscriptions of the drawings that the students created to illustrate the story. The story introduced students to chance experiments engaging them to decision making.

Yet again, in addition to all the possible benefits of 
creative endeavour, students' scripts provide researchers with an insight into students' components of thinking. The data also included students' answers to the following questions that were based on the story they were told in the lesson, a story about a princess's quest to save a prince: 1) Will the princess rescue the prince? 2) Which road should the princess take in order to have the highest chance of rescuing the prince?

The students were provided with the following materials: one container, two dice, two coins, counters (red, black and blue), a blank paper sheet (size A4), and coloured pencils.

The lesson was not videotaped, however, the author did observe several students in the class using their arms in preparing to create the diagrams or during the process of drawing. The set of gestures used as means of objectification were included in field notes taken by the first author, but they are not the focus of our data analysis. We have selected to focus on the signs, and inscriptions drawn by students and their relationship to students' components of thinking as illustrated by their drawings.

After a careful study of students' (We use pseudonyms when referring to each child) drawings, we identify salient characteristics illustrated by students' drawings. Focusing on the selected drawings, we carried out an analysis to study the students' components of thinking and the form of new structural relationships between these components as illustrated by the selected drawings; and the way that these relationships are illustrated to be organised and may be re-organised.

\section{Results and Discussions}

We describe here three episodes of the students' material components of thinking and the form of new structural relationships between these components, as illustrated by students' drawings, and the way that these relationships are oganised and re-organised. These were chosen to represent the diverse range of signs and inscriptions that were used. In our analysis we focus on the way that these relationships are oganised and may be re-organised.

\subsection{First Episode: Sampling without Replacement}

In this first example, the students attempted to illustrate the outcomes of their activity after their engagement with the random generators throughout the story and articulated the chance of all the possible outcomes. For example, when the story read that “...In the container you'll find 9 counters: 4 red, 2 black and 3 blue. Draw a counter from the container. If you choose a red counter, continue along this road and you'll find the prince. If the counter is black, go back to the castle and begin the travel again from there. If the counter is blue, take another counter (but do not return the blue counter back into the container)." Figure 2 illustrates the activity. Although Figure 2 shows the action of princess, and the reduction of the sample space, it certainty does not conform to the calculation of the most likely event when the sample space is changed by the occurrence of another event. To come up with an interpretation of student who drew Figure 2, let us note that generally speaking the students need to grasp the linkage of two different structures: one spatial and one probabilistic. While the students attend to the reduction of the sample space, they seemed to suggest an intermediate setting from which a sense of "numerical chance" or "conditional probability in a numerical form" emerges.

1 Anne: I am the princess. I drew one blue counter from the 9 counters (She pointed to her painting.) I did not return the counter back to the container. I then drew another blue counter from the 8 counters and I did not return the blue counter back to the container, and I drew one red counter from the 7 counters. I do not really know how to write the numbers.

2 George: It is like when we have cakes or pies and ... we cut the cake in 9 parts and three of those parts are blue.

3 Anne: I do not understand.

4 George: I will show to you. We have a cake (he drew a circle and he started dividing the circle in 9 parts, counting the parts aloud accompanying the counting process with a rhythmic upper body movement and pen-pointing gestures). We have three blue pieces from the nice pieces.

5 Anne: $\frac{3}{9}$

6 Researcher: What is $\frac{3}{9}$ ?

7 George: The fraction of blue.

8 Researcher: What pieces are blue? The pieces of the cake or the counters?

George and Anna were silent thinking.

9 George: Ehm...

10Anne: Ehm ... of the cake.

11Researcher: What did you draw a circle divided in 9 parts and you coloured parts in blue, George? What is $\frac{3}{9}$ ?

12George: $\frac{3}{9}$ is the fraction of the blue parts ... pieces of the cake. Well you know, I thought that we had 9 counters in the container, and I drew a cake divided in 9 pieces. $\frac{3}{9}$ is the fraction of the pieces of the cake, sooo $\frac{3}{9}$ is the fraction of the blue counters out of the 9 counters.

13Researcher: This is the number that we use to talk about the probability of drawing 1 blue counter (when we have 3 blue marbles) from the 9 counters.

14George: This is cool. I understand it.

The semiotic resources of the story telling here are produced by the synchronised linguistic activity of the researcher-student communication, the researcher's and students' gestures, and the drawings of figures/images of students.

The researcher did not want to lead students to draw a conclusion since this numericity was cognitively difficult for students of this age. These examples show the children's need to consider a third setting, fractions, with which they feel more familiar. The introduction of the fraction setting allowed students to adopt a different mode of reasoning (reasoning about fractions).This intermediate mode seemed to act as a tool that bridged the gap between the images drawn to represent princess's sampling process and numerical chance". 
15George: (pen-point to the divided circle) Do we eat 1 blue piece of cake now?

16Researcher: Yes. And then you take one blue piece of cake from the 8 pieces of cake and offer it to Anne.

17George: Can we draw a cake divided in 8 parts, colour the 2 blue portions and tell that the chance of drawing one marble from the 8 marbles is $\frac{2}{8}$ ? (George drew a circle, and divided the circle in 8 parts, colouring 2 parts of the circle in Blue).

Anne drew another counter from the container (pretending that she is the princess), and she illustrated in her drawing the princess to draw a red counter from the container, and then Anne started drawing a circle divided into 7 parts. She counted the number of red counters starting from right to left with pen-pointing gestures.

18Anne: Here we have $\frac{4}{7}$ probability of drawing 1 red counter from the 7 counters.

Anne and George were able to develop the ideas that the sample space changed in the without-replacement situations. The concrete materials that the students were provided with helped students to consider the number of elements of the target colour in relation to the entire sample space after the space has been modified by sampling without replacement.

Anne and George seemed to succeed in linking the spatial image and numerical chance by introducing another mediating setting that was acted as a bridge between the two components: spatial image and numerical chance.

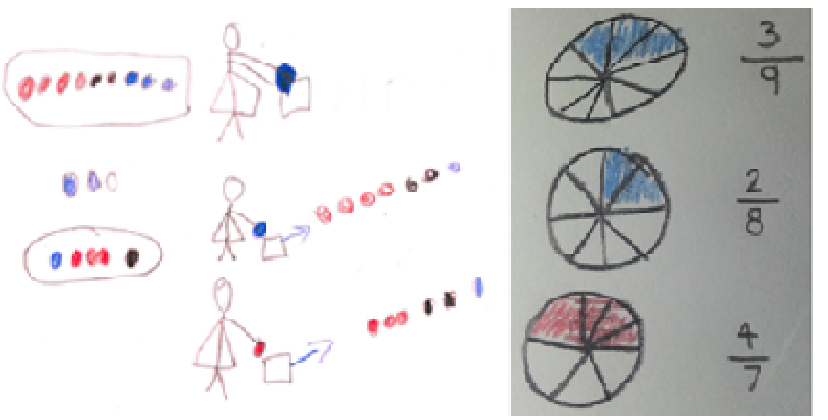

Figure 2. Anna's and George's drawings that illustrate the princess drawing counters from the container.

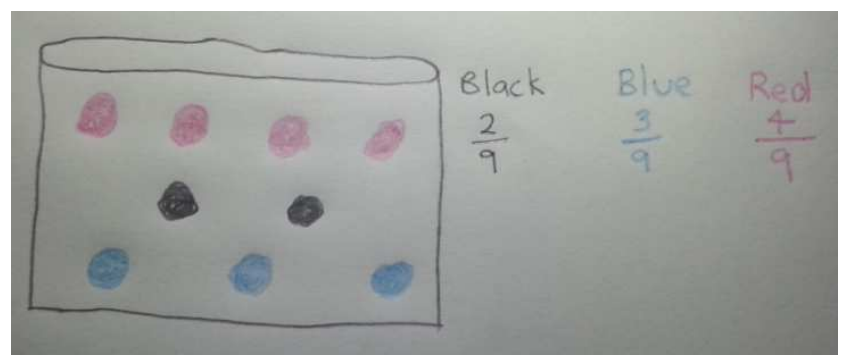

Figure 3. Example of other drawings that illustrate the container and the "chance numerical.

Nevertheless, their drawings can be compared to a group of other drawings (e.g., Figure 3), where images that illustrate the container and "chance numerical" are illustrated, but there is no indication of how young students linked these two components to a meaningful way. Figure 3 shows that, while students were able to calculate the fraction of the black, or blue, or red counters out of the total number of counters, they did not seemed aware of the changing number of elements comprising the sample space after a certain element was selected and did not returned back into the container. Young students' mode of thinking in Figure 3, are explicitly concerned with fractions.

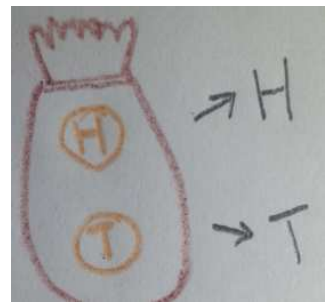

Figure 4. Drawing of a sample space of tossing a coin

\subsection{Second Episode: Sample Space of an Experiment or Random Trial}

In this second episode, young students illustrated the sample space of chance experiments listing all the possible outcomes. For example, when the story reads that "She flips a coin. If she gets head, she continues; if she gets tails she must return back to the castle. If the princess gets head: she travels along the forest and finally she arrives at the tower entrance."

In Figure 4, the student only illustrated the outcomes of the experiment of tossing a coin, drawing a money bag that included the set $\{$ head, tail $\}$.

\subsection{Third Episode: Complicated Sample Space}

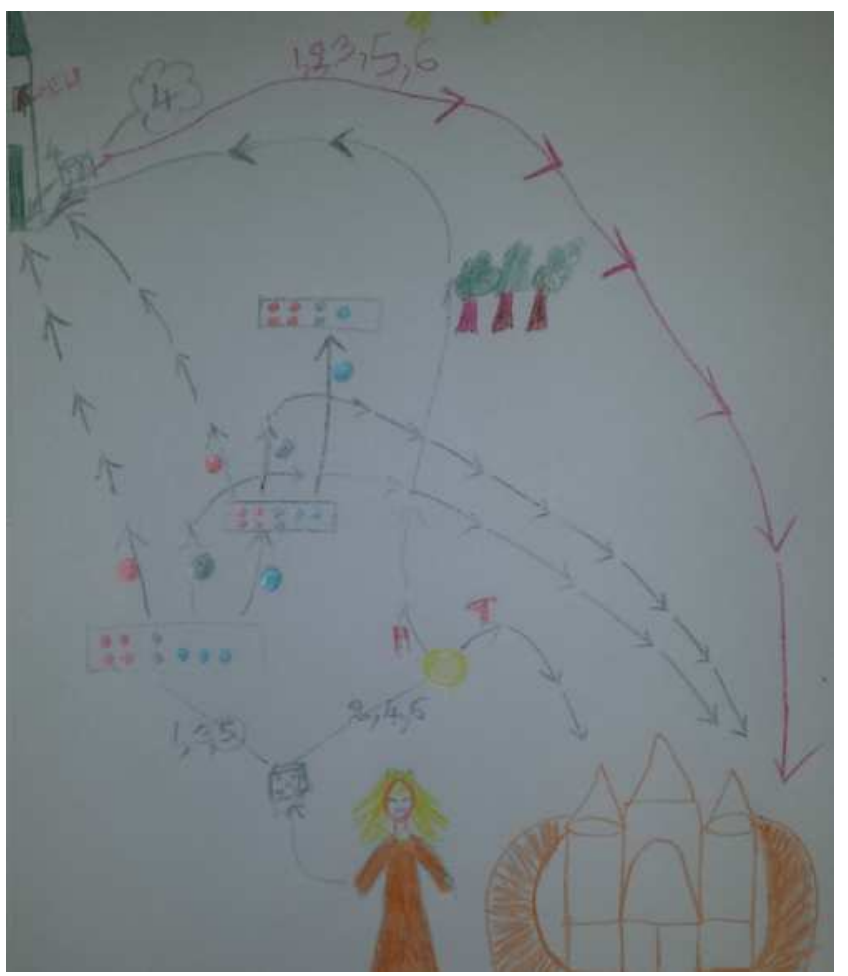

Figure 5. A part of Anna's and George's drawing.

In the third episode, two students, Emma and Josh worked 
together to map out the route of the journey of the princess. They did not use some of the available materials (the container; the two dice; the two coins; or the red, black, and blue counters). In their attempt to answer the question: "Which road should the princess take in order to have the highest chance of rescuing the prince?", these two students drew an illustration of the princess's journey that included the set of all possible routes, as determined by the outcomes of the target chance experiments. These two students drew Figure 5 in an orderly manner starting from the left hand side of the image of the princess and moving from bottom to left.

The students' idea was to list all the different possibilities of the princess's journey and taking into account not only the possible outcomes but also the different possibilities for or against to find out the road that the princess should take in order to have the highest chance of rescuing the prince.

Emma read the story and both students discussed how to create the route of the journey of the princess, systematically analysing the composition of sample space as illustrated in the form of a complicated tree diagram. The students were emphasizing the analytic process of listing the possible outcomes of a single chance experiment. Their perception of all the figures and the possible outcomes helped students to begin using probabilistic language. This is evident by the eloquently articulation of Josh:

19Josh: When the princess roll a die and gets ( 1 or 3 or 5) and then draws a red counter from the container that contains 9 counters ( 4 red, 2 black and 3 blue) she goes to rescue the prince. This road has the highest chance of rescuing the prince.

\section{Discussion}

This paper seeks contribute to the question of the development of young students' probabilistic thinking, when mathematics is taught as a Storytelling. Framed by the theory of objectification, thinking is considered mainly as a unity of material-ideational components-inner speech as expressed in young students' drawings, students' linguistic communications that, forms of sensuous visualisation, gestures used in students-student and research-student communications, etc. Development is considered to consist of young students' construction of two types of fundamental probabilistic ideas related to samples and sampling. The two fundamental ideas are about sampling without replacement and analysis of a sample space of an experiment that they appear as operational schemes relying on different semiotic means of objectification. When students reasoned about the images that illustrated the process of sampling without replacement, the students achieve a fixation of attention and extract from the undifferentiated horizon of images/objects certain elements that make apparent new objects/images for fractions. The selection of these images/objects to be transferred to another context (fractions) acts an intermediate step for the students or a bridging step that allows young students to work in a familiar setting from which a sense of "chance" or in particular "conditional probability" of the occurrence of an event emerges in a numerical form. This intermediate setting contributes to providing students with a perspectival view of the emergent conditional probability in the form of a fraction of a coloured part of a cake. These objects/images of our story act in a probabilistic setting (reinforced by storytelling) and a fractions setting because students transferred the objects/ images to a familiar setting for them, so students can act on those objects' images. As a result, these objects/images bear a very important characteristic: they do not seem to remain contextual objects due to their dual spatial-temporal model of being.

The analysis offered in this paper evidenced some tensions caused by a shifting in the relation between the objects/images of our story (probabilistic setting) and objects/images for fractions. This shifting in the knowledge from probability to Fractions provide the correct answers, however students now have to refer to the objects/images in a different way. After this shifting between Probability content and Fractions content, the numerical fractions have to be denoted using a "chance or probabilistic" language where they bear an existence as conditional probabilities. The didactic understanding of this shifting urges us to reflect on and envision new dialogical and semiotic forms of action in activities and interactive exercises for students on the topic of Probability that we propose to students during their insertion into the phylogenetical practice of probability.

Moreover, in the third episode, students were engaged in illustrating the princess's journey that included the set of all possible routes, as determined by the outcomes of the target chance experiments. The semiotic means of objectification in conjunction with the physical didactical tools (storytelling of an engaging story) encouraged young students to get engaged with the analysis of the sample space, a cognitively demanding aspect of probabilistic thinking [11]. Having young students concentrate on drawing the whole set of possible results when dealing with random situations, sheds some light on the question about young students' development of probabilistic thinking.

While we do not wish to overgeneralize from our specific observations, this article shows how some young students' actions and semiotic objectification processes played a crucial role in the development of their probabilistic thinking. Our analyses offer a glimpse into the evolution of probabilistic thinking in some young students, an evolution that might not apply to all students, but that at least offers a framework for further investigation into these patterns of probabilistic thinking. The work in this article contrasts Piaget and Inhelder's ([12],1974 / 1951) work about the growth and structure of mental operations of probabilistic as part of their theory on researching stages of intellectual development. We suggest that the semiotic means of objectification within our theoretical framework provide the experiences, culture, and tools necessary for the young students to build new psychological functions about probability. This work might be conceptualised as occurring in a zone of proximal development [13] out of which young students construct new psychological functions. 
In conclusion, this study's findings suggest that the coordination and the dynamics of semiotic resources produced by the researcher-young students' interaction, including the images, gestures, forms of imagination and visualisation, could have a major role in young students' active and effective involvement with mathematics in a teaching-learning process when teaching Mathematics as Storytelling. Future research could focus on how several semiotic systems (e.g., gestures, signs, inscriptions, inner and outer speech) and their connections to different processes of teaching Mathematics as storytelling might enhance young students' involvement and learning mathematics.

\section{References}

[1] Columba, L., Kim, C., \& Moe, A. J. (2005). The power of picture books in teaching math and science: Grades PreK-8. Scottsdale, AZ: Holcomb Hathaway.

[2] Zazkis, R., and Liljedahl, P. (2009) Teaching Mathematics as Storytelling. Rotterdam: Sense publishers.

[3] Haven, K. (2000). Super simple storytelling: A can-do guide for every classroom, every day. Englewood, CO: Teacher Ideas Press.

[4] Godino, J. D., Font, V., Wilhelmi, M.R., Lurduy, O. 2011; Why is the learning of elementary arithmetic concepts difficult? Semiotic tools for understanding the nature of mathematical objects. Educational Studies in Mathematics, 77 (2-3), 247-265.

[5] Edwards, L. (2009). Gestures and conceptual integration in mathematical talk. Educational Studies in Mathematics, 70, 127-141.

[6] Radford, L. (2008a). The ethics of being and knowing: Towards a cultural theory of learning. In L. Radford, G. Schubring, \& F. Seeger (Eds.), Semiotics in mathematics education: Epistemology, history, classroom and culture (pp. 215-234). Rotterdam: Sense Publishers.

[7] Radford, L. (2008b). Connecting theories in mathematics education: challenges and possibilities. ZDM Mathematics Education. 40, 317-327.

[8] Radford, L. (2009). Why gestures matter? Sensuous cognition and the palpability of mathematical meanings. Educational Studies in Mathematics, 70(3). 111-126.

[9] Radford, L. (2001). Factual, Contextual and Symbolic Generalizations in Algebra, in: Proceedings of the 25th Conference of the International Group for the Psychology of Mathematics Education, Marja van den Hueuvel-Panhuizen (ed.), Freudental Institute, Utrecht University, The Netherlands, Vol.4, pp.81-88.

[10] Australian Curriculum, Assessment and Reporting Authority. (2010). Australian Curriculum: Mathematics. Version 1.2. Retrieved March 15, 2011, from http://www.acara.edu.au

[11] Fischbein, E. (1975). The intuitive sources of probabilistic thinking in children. Dordrecht, The Netherlands: Reidel.

[12] Piaget, J., \& Inhelder, B. (1975). The origin of the idea of chance in students (L. Leake, Jr., P. Burrell, \& H. D. Fischbein, Trans). New York: Norton (Original work published 1951).

[13] Vygotsky, L. (1978). Mind in society. Cambridge, Mass: Harvard University Press. 